\title{
Е.М. Кабунова
}

\section{ИЗ ИСТОРИИ ФОРМИРОВАНИЯ И ЭКСПОНИРОВАНИЯ КОЛЛЕКЦИИ ИСКУССТВА СТРАН ВОСТОКА В СОБРАНИИ ИРКУТСКОГО ОБЛАСТНОГО ХУДОЖЕСТВЕННОГО МУЗЕЯ ИМ. В.П. СУКАЧЕВА}

\begin{abstract}
Статья посвящена истории формирования и экспонирования коллекции восточного (в частности, буддийского) искусства в собрании Иркутского областного художественного музея им. В.П. Сукачева. На основе архивных источников, документации отдела хранения, работы с подлинниками автором сделана попытка выявить, систематизировать и проанализировать экспозиционно-выставочную деятельность музея на примере собрания «Искусство стран Востока».

Ключевые слова: Иркутский областной художественный музей им. В.П. Сукачева, искусство Востока, буддийское искусство, коллекция, экспозищия.
\end{abstract}

Иркутский областной художественный музей им. В.П. Сукачева (ИОХМ) обладает уникальной коллекцией искусства Востока, насчитывающей около 2500 произведений (Китай, Япония, Индия, Монголия).

Такому богатому наследию музей во многом обязан ВосточноСибирскому отделу Императорского Русского географического общества (ВСОИРГО), созданному в 1851 г. Экспедиции ведущих членов ВСОИРГО (Г. Потанин, Д. Гомбоев, И. Подгорбунский и др.), возвращаясь из сопредельных стран, привозили разнообразные предметы культуры и быта, в том числе произведения искусства. К началу ХХ в. Иркутский отдел Русского географического общества обладал довольно основательной коллекцией, которая хранилась в созданном при нем музее [1. С. 15].

Значительная часть привезенных предметов, представленных в музее ВСОИРГО, после национализации перешла в фонды Музея народоведения (позже - Иркутский областной краеведческий музей, при котором до 1936 г. художественный музей существовал как галерея).

К концу 1926 г. в картинной галерее, располагавшейся тогда по адресу ул. Халтурина, 1 (бывший дом купца Файнберга), функционировали отделы: 1 - иконографии, 2 - академистов, 3 - передвижников, 4 - западноевропейского искусства, 5 - «Мира искусства», 6 - сибирского искусства, 8 - прикладного искусства, 7 - азиатского искусства [2. С. 150].

Ставший в 1934 г. хранителем и директором галереи Г.И. Дудин значительно развернул отделы западноевропейского, русского, а также японского и китайского искусства. Сохранившиеся фотографии того периода позволяют увидеть, что в экспозиции галереи преимущественно были представлены японский и китайский фарфор, резьба по кости и деревянная скульптура. Однако, как пишет бывший директор музея А.Д. Фатьянов в своих воспоминаниях, «находившаяся в составе Краеведческого музея галерея не пользова- 
лась должным вниманием со стороны дирекции, т.к. основной целью музея было улучшение работы отделов, связанных с краеведением» [3. С. 35].

Постановлением Восточно-Сибирского крайисполкома от 25 апреля 1936 г. и приказом Наркома просвещения от 1 июля 1936 г. № 484 картинная галерея была выделена из состава Краеведческого музея и передана Управлению по делам искусств Иркутского краевого исполнительного комитета [4. Л. 31].

Часть восточной коллекции бывшего музея ВСОИРГО была передана в художественный музей (с 25.04 по 05.12.1936 г. - Восточно-Си-бирский краевой художественный музей; с 05.12.1936 по 26.09.1937 г. - ВосточноСибирский областной художественный музей; с 26.09.1937 по 01.10.1990 г. Иркутский областной художественный музей; с 01.10.1990 по 27.11.1995 г. Иркутский областной художественный музей им. В.П. Сукачева; с 27.11.1995 г. - Государственное учреждение культуры Иркутский областной художественный музей им. В.П. Сукачева) и впоследствии становится основой восточного собрания, крупнейшего на территории Восточной Сибири [5. Л. 7].

В 1951 г. музею, коллекция которого значительно выросла за этот период, выделяют новое помещение, расположенное на центральной улице Иркутска (К. Маркса, 23). В новом здании, помимо отделов русского и западноевропейского искусства, был открыт отдел «Искусство Китая», который располагался в двух залах. В первом экспонировались памятники искусства различных эпох - от II тыс. до н. э. вплоть до XIX столетия. Второй зал знакомил зрителей с современным искусством Китая [2. С. 53].

Культура и творчество мастеров Японии и Монголии в экспозиции представлены не были, что во многом объяснялось острой нехваткой площадей. Демонстрация этих восточных коллекций была возможна лишь в рамках временных и передвижных выставок. В 1973 г. решением обисполкома Совета депутатов трудящихся Художественному музею, располагавшемуся до этого в двухэтажном каменном особняке на ул. К. Маркса, 23, передается историческое здание по ул. Ленина, 5. Построенное в 1905-1907 гг. по проекту архитектора Д.Р. Магидей, оно изначально предназначалось для первой в Сибири Губернской мужской гимназии.

После ремонта и реконструкции 29 сентября 1975 г. впервые открылись двери нового здания, где разместилась постоянная экспозиция. Однако, со слов бывшего директора ИОХМ А.Д. Фатьянова, изначально коллекцию стран Востока планировалось показывать на постоянной основе в 3-м корпусе музея - соборе Богоявления. В этом филиале музея сотрудники планировали разместить первобытное и древнерусское искусство, а также искусство Востока (Китай, Япония, Монголия, Индия) [6. Л. 2].

Располагая богатейшей коллекцией русского, западноевропейского и восточного искусства, Иркутский художественный музей тем не менее не имел до 2001 г. постоянной экспозиции искусства стран Востока, хотя интерес к восточной культуре со стороны посетителей, безусловно, был, о чем свидетельствуют данные архива ИОХМ - документы о проведении выставок (каталоги, буклеты, пригласительные билеты, статьи и т.д.), а также акты Отдела хранения музея. 
В послевоенные годы особой популярностью в Иркутске пользовались выставки искусства Китая. В 1950 г. создается выставка «Советская графика», а в конце того же года в связи со второй годовщиной Китайской Народной Республики из фондов музея была организована выставка китайского изобразительного искусства, которая работала до марта 1951 г. На ней было представлено свыше 500 предметов народного творчества Китая со II в. до н.э. и до начала XX столетия, а также был издан каталог-путеводитель.

В 1955 г. состоялась передвижная выставка китайского изобразительного искусства, размещенная в агитпоезде на железнодорожной магистрали Иркутск-Мысовая. Такая же выставка была организована для трудящихся на строительстве Иркутской ГЭС. Работа над выставочным проектом также сопровождалась печатью каталога.

В 1957 г. в Иркутском художественном музее прошла выставка из частных собраний жителей Иркутска, состоящая из произведений китайского народного творчества. Подобных выставок китайского искусства, как отмечает А.Д. Фатьянов, в нашей стране не организовывалось, и первенство в этом отношении принадлежит Иркутскому художественному музею [2. С. 62].

Начиная с 1960-х гг. популярностью пользовались привозные выставки, раскрывающие культурные традиции и других стран восточного региона: «Прикладное искусство Монголии» (1966 г.) [7. Л. 1], «Выставка современного искусства Индии» (1980 г.) [8. Л. 43], «Выставка монгольского искусства» (1981 г.) [9. Л. 31], «Индия, Япония, Китай» (1984 г.) [10. Л. 78], «Зарубежный Восток» (1984 г.) [11. Л. 45] и т.д.

В 1980-е гг. в Иркутском художественном музее с большим успехом прошли несколько крупных выставочных проектов из собрания Государственного Эрмитажа: «Тибетское искусство из собрания Государственного Эрмитажа» (1987 г.) [12. Л. 65], «Японская гравюра XVIII-XIX вв. и нэцкэ из собрания Эрмитажа» (1988 г.) [13. Л. 83], «Китайское прикладное искусство XIV-XIX вв.» (1989 г.) [14. Л. 17].

Необходимо отметить, что с 1980-х гг. начинается тесное и плодотворное сотрудничество Иркутского областного художественного музея и Государственного Эрмитажа не только в сфере выставочной деятельности, но и в области реставрации культурного наследия народов мира. В период с 1987 г. реставраторами Эрмитажа было спасено и возвращено к жизни более 200 произведений графического искусства Востока из фондов ИОХМ - японская гравюра укие-э, китайский лубок и буддийская живопись танка [15. C. 2].

Отреставрированные экспонаты, многие из которых являются уникальными памятниками культуры и истории и не имеют аналогов в музейных коллекциях России, хотелось продемонстрировать зрителям. В книгах отзывов все чаще встречались просьбы о выставках, посвященных искусству и культуре стран азиатского региона. Назрела серьезная необходимость в постоянной экспозиции «Искусство стран Востока», для разработки проекта которой была проведена серьезная научно-исследовательская работа с фондами, данными инвентарных книг и каталогов. В плане работы музея на 2000 г. среди приоритетных направлений деятельности музея значится: «В экспозиционно-выставочной работе основным направлением явится соз- 
дание стационарных экспозиций по важнейшим разделам коллекции, а именно: искусства зарубежного Востока и искусства Сибири» [16. Л. 3].

В 2000 г. ведущими специалистами ИОХМ И.Г. Федчиной, И.И. Шинковым и А.М. Парфененко был разработан концептуальный план постоянной экспозиции «Искусство Востока», который был впоследствии реализован в экспозиционном пространстве трех залов и коридора первого этажа основного здания музея на Ленина, 5.

Самую значительную часть коллекции стран Востока в собрании ИОХМ, как было сказано ранее, составляет искусство Китая, насчитывающее около 1400 экспонатов. Искусство Японии включает 700 с небольшим произведений, собрание индийского искусства - примерно 300, творчество мастеров Монголии представляют 100 экспонатов. В постоянную экспозицию было решено включить произведения трех стран - Китая, Японии и Монголии.

Для каждой страны были разработаны своя концепция и тематикоэкспозиционный план. Основным принципом построения экспозиции был выбран тематический, так как разрозненность коллекции не позволила представить развитие искусства в хронологическом порядке. Основой показа в большинстве случаев стал материал: дерево, фарфор, металл и т.д., а главной задачей экспозиции определили демонстрацию наиболее ярких образцов культуры и искусства стран Востока, показ основных видов художественного творчества и стилевых направлений.

Наиболее разнообразной и ценной в собрании ИОХМ является коллекция искусства Китая, в которой имеются практически все виды изобразительного искусства (дерево, кость, лаки, бронза, фарфор, графика и т.д.), начиная c XIV столетия. В экспозиции «Искусство Китая», которая по проекту организаторов заняла два зала, тематически представлено как классическое, так и народное искусство. Уже 1 сентября 2000 г. по новой экспозиции музея была проведена экскурсия для воспитанников сиротского кадетского училища [17. Л. 16].

Экспозиция «Искусство Японии», которая лишь в 2009 г. заняла на постоянной основе предназначенный для нее один зал (до этого японское искусство было представлено лишь фрагментарно в коридоре восточной экспозиции), демонстрирует лучшие образцы гравюры укие-э, предметы прикладного искусства - лаки, резьбу по кости, керамику, нэцкэ.

Экспозиция «Искусство Монголии и Бурятии», раскрывающая на примере живописи танка искусство буддизма, расположилась в силу своего немногочисленного состава в коридоре - в рамах и специально изготовленных киотах.

Современное собрание буддийской живописи в Иркутском художественном музее насчитывает 62 произведения, из которых большая часть представляет живопись на холсте минеральными красками. В основном это небольшие танка размерами $25 \times 35 \mathrm{~cm}$, написанные мастерами Монголии и Бурятии. Значительную часть собрания (53 предмета) составляют иконы, переданные в 1925 и 1936 гг. этнографическим отделом Иркутского государственного музея бывшего ВСОИРГО. Очевидно, они были привезены как этнографический материал из научно-исследовательских экспедиций по странам Азии [18. С. 173]. 
Можно говорить о том, что первоначально коллекция буддийской традиционной живописи формировалась бессистемно и неупорядоченно. Отсутствие специалистов по искусству буддизма нередко приводило к путанице в заполнении инвентарных книг, а ряд общих поверхностных загрязнений и повреждений (потемнения от копоти и сажи, осыпи красочного слоя, мятины, фрагментарные утраты холста) осложняли работу по атрибуции и выявлению живописных особенностей произведения.

К сожалению, нужно отметить, что коллекция танка из собрания музея не дает возможности проследить историю возникновения и развития этого вида искусства, так как экспонируются в основном работы XIX в. Но дать общее представление об этом виде буддийского искусства, познакомить с каноном, иконографией божеств пантеона экспозиция может. Изначально для выставки было отобрано 15 танка, призванных продемонстрировать основные иконографические типы - Будды Шакьямуни, Цзонхавы, бодхисаттв, образы гневных божеств - защитников веры.

Период начала 1990-х гг. отмечен все более возрастающим интересом к традиционной культуре стран азиатского региона. Повышенным интересом стали пользоваться выставки, посвященные тематике буддийского искусства. В 1995 [19. Л. 70], 2008 [20. Л. 36] и 2011 гг. [22. Л. 17] в стенах ИОХМ с большим успехом прошли персональные выставки профессионального буддийского иконописца Николая Дудко, на которых, помимо живописи танка, была представлена ритуальная бронзовая скульптура из собрания Иркутского художественного музея и коллекции автора. Выставки сопровождались встречами с живописцем, лекциями и экскурсиями.

В 2004 г. в музее была открыта выставка «Танка. Связь традиции и современности» [23. Л. 23], на которой, помимо 11 икон танка от Н. Дудко, впервые во всем многообразии (около 50 предметов) экспонировались произведения буддийского искусства из личного собрания известного иркутского коллекционера А. Иващенко. Формат данной выставки был необычным, а выбранные для проекта уникальные экспонаты вызвали большой интерес у аудитории. Посетители выставки смогли увидеть скульптуру, произведения декоративно-прикладного искусства, танка мастеров Тибета, Китая, Бурятии $\mathrm{XIX}-\mathrm{XX}$ вв.

В 1992 и 2011 гг. в целях укрепления межрегиональных отношений и связей в области культурного и духовного сотрудничества между Республикой Бурятия и Иркутской областью состоялись два крупных выставочных проекта. Первый - в 1992 г. в г. Улан-Удэ под названием «Буддийская живопись танка из собрания Музея истории Бурятии» [24. Л. 54], открытие второго «Сокровища буддийского искусства Бурятии» - состоялось в 2012 г. [Там же. Л. 87] Свыше 70 произведений буддийского искусства из запасников Национального музея Республики Бурятия впервые демонстрировались в Иркутске.

На совершенно новом уровне взаимодействия истории и культуры религиозных конфессий, существующих на территории Восточной Сибири, была выстроена выставка «Дорога к храму. Путь каждого» (в рамках общегородского проекта «Дорога к храму») [25. Л. 2], которая открылась в 2013 г. в Иркутском художественном музее. Экспозиция знакомила с основами и традициями православия, католицизма, буддизма, ислама и иу- 
даизма. Раздел, посвященный буддийской храмовой культуре, помимо предметов из собрания иркутского дацана, дополнили экспонаты из собрания художественного музея.

Востребованность традиционной культуры центрально-азиатского региона, интерес к философии и истории буддизма, проявившиеся с особой силой в этот период выставочной деятельности музея, свидетельствовали о необходимости увеличения выставочного пространства «Искусство стран Востока» и введении в экспозицию новых произведений.

Начиная с 2001 г. автором данной статьи велась активная работа по корректировке атрибуционных данных буддийской коллекции танка. Были уточнены хронологические рамки некоторых работ, иконография божеств, место создания произведений. Полученные данные позволили ввести в экспозиционный ряд новые иконы, раскрывающие важные иконографические сюжеты и дополняющие основную идею выставки («Белая Тара», ЖА-143; «Палдан Лхамо», Ж-2346; «Доржи Наг-по», Ж-2345; «Цаган Убугун», Ж-2477 и т.д.). После реставрации в мастерских Государственного Эрмитажа постоянное место в выставочном пространстве заняла одна из лучших икон в собрании музея - танка «Белая Тара» (ЖА-263), написанная на шелке и поступившая из коллекции ВСОИРГО.

Изначально в экспозиции буддийской живописи были представлены в основном произведения XIX в. В 1990-2000-е гг. собрание буддийского искусства ИОХМ пополнилось иконами современных мастеров. В 1995 г. у Н. Дудко была приобретена танка «Гуру Падмасамбхава» (Ж-2389). В 2001 г. от Н.Д. Дондоковой - живописца и искусствоведа - поступили как дар и как закупка две танка - «Хуман-хан» (Ж-2414) и «Бурун-хан» (Ж-2411), одна из которых была написана ее отцом Данзаном Дондоковым, выдающимся иконописцем XX в.

Таким образом, в настоящее время в экспозиции можно увидеть не только образцы буддийской живописи XIX в., но и, проследив преемственность традиций, творчество современных иконописцев.

Кроме того, в 2000-е гг. экспозиция «Искусство Монголии» дополнилась несколькими новыми витринами-столиками, что позволило расширить выставочные возможности и ввести в экспозицию предметы культового назначения мастеров Монголии и Бурятии: ритуальные чаши для подношений, гау (буддийские амулетницы), цакли (особый жанр тибетской живописи, иконы небольшого размера), ваджры и т.д.

Научно-исследовательская работа, которую на протяжении многих десятилетий вели сотрудники музея, позволила реализовать в июле 2016 г. один из серьезнейших выставочных проектов последнего времени. В рамках проекта «Открываем запасники» была развернута выставка «Многоликий Восток» [26. Л. 1-10], которая продемонстрировала работы, редко или никогда ранее не экспонируемые. В экспозицию вошло искусство Индии, Китая, Японии и Монголии XIX-XX вв.: живописные полотна, культовая скульптура, мелкая пластика, украшения из серебра, традиционная керамика - всего 138 произведений из фондов Иркутского областного художественного музея. Авторы выставочного проекта хотели показать яркую и самобытную культуру этих стран, а также преломление вековых традиций в современном искусстве. 
Особое место на выставке заняли и образцы буддийского искусства: живопись танка, бронзовая скульптура, предметы ритуального культа всего около 40 предметов. Экспонаты представлены в их взаимосвязи с культурно-историческим контекстом тех стран или регионов (Китай, Монголия, Бурятия), в которых философия и искусство буддизма нашли свое яркое воплощение.

Вопросы формирования и экспонирования коллекции восточного искусства в собрании ИОХМ, а также проблема ее современного бытования достаточно, на наш взгляд, актуальны. Малоизучена пока коллекция буддийской бронзовой пластики ИОХМ, отдельного внимания требует работа с архивами и фондами Иркутского областного краеведческого музея. Последующая научно-исследовательская деятельность, направленная на изучение, сохранение и восстановление памятников буддийской культуры, позволит в дальнейшем расширить и обогатить экспозиционновыставочный потенциал музея, окажет содействие комплектованию фондов, а также даст возможность продемонстрировать зрителям уникальные экспонаты, хранящиеся в его запасниках.

\section{Литература}

1. Шинковой А.И. Японская цветная гравюра: Каталог. М. : ВРИБ Союзрекламкультура, $1990.88 \mathrm{c}$.

2. Фатьянов А.Д. Записки Иркутского областного краеведческого музея. Иркутск, 1958. $159 \mathrm{c}$.

3. Фатьянов А.Д. Иркутский художественный музей. Иркутск : Иркутское книжное издательство, 1958. $122 \mathrm{c.}$

4. ГАИО. Ф.Р-47. Оп. 1. Д. 95. Л. 31.

5. Архив ИОХМ. Оп. 1. Л. 7.

6. Архив ИОХМ. Оп. 1. Л. 2.

7. ИОХМ. Акт приема на временное пользование № 89 от 10.12.1966. Л. 1.

8. ИОХМ. Акт приема на временное пользование № 206 от 21.01.1989. Л. 43.

9. ИОХМ. Акт приема на временное пользование № 220 от 15.06.1981. Л. 31.

10.ИОХМ. Акт приема на временное пользование № 257 от 05.1984. Л. 78.

11.ИОХМ. Акт приема на временное пользование № 256 от 18.04.1984. Л. 45.

12.ИОХМ. Акт приема на временное пользование № 379 от 26.06.1987. Л. 65.

13.ИОХМ. Акт приема на временное пользование № 41 от 3.08.1988. Л. 83.

14.ИОХМ. Акт приема на временное пользование № 45 от 8.09.1989. Л. 17.

15. Спасенные сокровища. Реставрация графики Востока из коллекции ИОХМ в Государственном Эрмитаже: Каталог выставки. Иркутск : Артиздат, 2003. 12 с.

16.Архив ИОХМ. Оп. 1. Л. 3.

17.Архив ИОХМ. Оп. 1. Л. 16.

18.Кабунова E.M. Формирование коллекции восточного искусства в Иркутском областном художественном музее им. В.П. Сукачева // Наука, образование, музеи : формы освоения наследия: сб. науч. ст. / отв. ред. В.А. Ламин, О.Н. Труевцева, О.Н. Шелегина. Барнаул; Новосибирск: Триада, Институт истории Сибирского отделения Российской академии нау», 2016. 204 c.

19.ИОХМ. Акт приема на временное пользование № 44 от 19.10.1995. Л. 70.

20.ИОХМ. Акт приема на временное пользование № 35 от 3.03.2008. Л. 36.

21.ИОХМ. Акт приема на временное пользование № 363 от 27.05.2011. Л. 17.

22.ИОХМ. Акт приема на временное пользование № 199 от 16.04.2004. Л. 23.

23.ИОХМ. Акт приема на временное пользование № 21 от 8.06.1992. Л. 54.

24.ИОХМ. Акт приема на временное пользование № 372-12 от 11.04.2012. Л. 87.

25.ИОХМ. Акт приема на временное пользование № 1438 от 03.09.2013. Л. 2.

26.ИОХМ. Акт приема на временное пользование № 1909 от 06.07.2016. Л. 1-10. 
Kabunova Elena M. Sukachev Irkutsk Regional Art Museum (Irkutsk, Russian Federation).

E-mail: alena-kabunova@yandex.ru

Tomsk State University Journal of Cultural Studies and Art History, 2017, № 25. 147-155 pp.

DOI: $10.17223 / 22220836 / 25 / 18$

HISTORY OF FORMATION AND EXHIBITION OF THE COLLECTION OF ORIENTAL COUNTRIES IN SUKACHEV IRKUTSK REGIONAL ART MUSEUM

Key words: Sukachev Irkutsk Regional Art Museum, Oriental art, Buddhist art, collection, exposition.

The article presents key moments of formation and life of the collection of Oriental (in particular, Buddhist) art in Sukachev Irkutsk Regional Art Museum. Based on archive sources and documents of the Department of conservation as well as on the studying of original artworks, the author made an attempt to determine, to systematize and to analyze exhibition activity of Irkutsk Regional Art Museum through the example of the collection "Art of Oriental countries".

Irkutsk Regional Art Museum has a unique collection of Oriental art of more than 2500 works of art from China, Japan, India, Mongolia. This collection is one of the largest and the most significant in of Siberian and Ural regions.

Among the main sources of formation of Oriental art collection of Sukachev Irkutsk Regional Art Museum, the contribution of the East Siberian Branch of Imperial Russian Geographical Society requires special attention. According to the documents of holdings of the Irkutsk Regional Art Museum (books of acquisition), significant part of works of Oriental art passed into museum's possession from ethnographic department of Irkutsk State Museum of former East Siberian Branch of Imperial Russian Geographical Society in 1920-1930s.

The article reviews the history of exhibition activity of the department of Oriental art of Sukachev Irkutsk Regional Art Museum in different periods - from the first decades of $20^{\text {th }}$ century, when Irkutsk Regional Art Museum was just a gallery of Irkutsk Regional Museum of Local Lore, History and Economy, up until now. A detailed account is given to the activity of the museum in 1990-2000s. In this period, plan of exhibition projects of permanent exposition "Oriental Art" (displayed in the main building of the museum at Lenin str., 5) was developed. After the analysis of exhibition activity of Sukachev Irkutsk Regional Art Museum related to the exhibitions of Oriental art (exhibitions from other museums; exhibitions dedicated to the particular themes; exhibitions based on the museum's own collection, etc.) over a previously mentioned period, relevance and importance of this decision were proved by the author of the article.

Individual attention was paid to the problems of existence and attribution of works of Buddhist art. Buddhist art is presented in the permanent exposition "Mongolian Art" by traditional Buddhist painting - thangka. The author of the article describes this collection, main stages of its acquisition, conservation, restoration, studying and exhibition, and also points out the unique character of the collection and necessity of its further development and research.

\section{References}

1. Shinkovoy, A.I. (1990) Yaponskaya tsvetnaya gravyura: Katalog [Japanese color engraving: A catalog]. Moscow: VRIB Soyuzreklamkul'tura.

2. Fatyanov, A.D. (1958) Zapiski Irkutskogo oblastnogo kraevedcheskogo muzeya [Notes of the Irkutsk Regional Museum of Local Lore]. Irkutsk: [s.n.].

3. Fatyanov, A.D. (1958) Irkutskiy khudozhestvennyy muzey [The Irkutsk Museum of Arts]. Irkutsk: Irkutskoe knizhnoe izdatel'stvo.

4. The State Archives of Irkutsk Region. Fund R-47. List 1. File 95.

5. The Arhives of the Irkutsk Regional Museum of Arts. List 1. P. 7.

6. The Archives of the Irkutsk Regional Museum of Arts. List 1. P. 2.

7. The Irkutsk Regional Museum of Arts. Act of acceptance for temporary use No. 89 of December 10, 1966. P. 1.

8. The Irkutsk Regional Museum of Arts. Act of acceptance for temporary use No. 206 of January 21, 1989. P. 43.

9. The Irkutsk Regional Museum of Arts. Act of acceptance for temporary use No. 220 of June 15, 1981. P. 31.

10. The Irkutsk Regional Museum of Arts. Act of acceptance for temporary use No. 257 of May, 1984. P. 78. 
11. The Irkutsk Regional Museum of Arts. Act of acceptance for temporary use No. 256 of April 18, 1984. P. 45.

12. The Irkutsk Regional Museum of Arts. Act of acceptance for temporary use No. 379 of June 26, 1987. P. 65.

13. The Irkutsk Regional Museum of Arts. Act of acceptance for temporary use No. 41 of August 3, 1988. P. 83.

14. The Irkutsk Regional Museum of Arts. Act of acceptance for temporary use No. 45 of September 8, 1989. P. 17.

15.Anon. (2003) Spasennye sokrovishcha. Restavratsiya grafiki Vostoka iz kollektsii IOKhM v Gosudarstvennom Ermitazhe: Katalog vystavki [The saved treasure. Restoration of the East graphics from the collection of The Irkutsk Regional Museum of Arts in the State Hermitage Museum: An exhibition catalog]. Irkutsk: Artizdat.

16. The Archives of the Irkutsk Regional Museum of Arts. List 1. P. 3.

17. The Archives of the Irkutsk Regional Museum of Arts. List 1. P. 16.

18. Kabunova, E.M. (2016) Formirovanie kollektsii vostochnogo iskusstva v Irkutskom oblastnom khudozhestvennom muzee im. V.P. Sukacheva [The formation of the Oriental collection in the Irkutsk Regional Museum of Arts]. In: Lamin, V.A., Truevtseva, O.N. \& Shelegina, O.N. (eds) Nauka, obrazovanie, muzei: formy osvoeniya naslediya [Science, education, museums: Forms of heritage development]. Barnaul; Novosibirsk: Triada, Institute of History of the Siberian Branch of the Russian Academy of Sciences.

19. The Irkutsk Regional Museum of Arts. Act of acceptance for temporary use No. 44 of October 19, 1995. P. 70.

20. The Irkutsk Regional Museum of Arts. Act of acceptance for temporary use No. 35 of March 3, 2008. P. 36.

21. The Irkutsk Regional Museum of Arts. Act of acceptance for temporary use No. 363 of May 27, 2011. P. 17.

22. The Irkutsk Regional Museum of Arts. Act of acceptance for temporary use No. 199 of April 16, 2004. P. 23.

23. The Irkutsk Regional Museum of Arts. Act of acceptance for temporary use No. 21 of June 8, 1992. P. 54.

24. The Irkutsk Regional Museum of Arts. Act of acceptance for temporary use No. 372-12 of April 11, 2012. P. 87.

25. The Irkutsk Regional Museum of Arts. Act of acceptance for temporary use No. 1438 of September 3, 2013. P. 2.

26. The Irkutsk Regional Museum of Arts. Act of acceptance for temporary use No. 1909 of July 6, 2016. P. 1-10. 